\title{
Notas arendtianas sobre La República de Rosler
}

\author{
Arendtian Notes On The Republic of Rosler
}

Paula Hunziker

Recepción de la propuesta: 09/08/2018

Evaluación y aceptación: 10/09/2018

Recepción y aceptación final: 13/02/2020

\begin{abstract}
Resumen: El presente trabajo busca establecer un diálogo con el libro de Andrés Rosler Razones Públicas. Seis Conceptos sobre La República. En primer lugar, nos concentramos en la idea arendtiana de pensar juntos el concepto republicano clásico de "debate político" y el desempeño de la "facultad de juzgar" (que prosigue Rosler), así como en la posibilidad de su actualización bajo condiciones de "modernidad". En segundo lugar, proponemos otra lectura de la libertad republicana clásica: una que pone en el centro la idea de participación del pueblo (lo cual no supone simplemente una defensa de la "libertad positiva" griega, sino de su lectura romana, que la conserva y amplía). En tercer lugar, proponemos revisar la ejemplaridad del Bruto republicano, tal como es defendida por el autor del libro a partir del Julio César de Shakespeare.
\end{abstract}

Palabras clave: Rosler, Republicanismo, debate político, Bruto, Shakespeare

\begin{abstract}
The present work seeks to establish a dialogue with Andrés Rosler's book Public Reasons. Six Concepts on The Republic. First, we focus on the Arendtian idea of thinking together about the classic republican concept of "political debate" and the performance of the "faculty of judging" -which Rosler continues-, as well as the possibility of updating it under

* Licenciada y Doctora en Filosofía, Escuela de Filosofía y Centro de Investigaciones de la Facultad de Filosofía y Humanidades, FFyH-UNC, Córdoba, Argentina. Correo electrónico: paulahunziker@gmail.com
\end{abstract}


conditions of "modernity". Secondly, we propose another reading of classical republican freedom: one that puts the idea of people's participation at the center -which is not merely a defense of Greek "positive freedom", but of its Roman reading, which preserves and expand it. Third, we propose to review the exemplarity of the Republican Bruto, defended by the author of the book through an analysis of Shakespeare's Julio César.

Keywords: Rosler, Republicanism, Political debate, Bruto, Shakespeare

Es duro decir la verdad, pues solo hay una, Pero está viva y tiene por ello un rostro vivo cambiante

F. Kafka.

En el texto tardío Las hojas del ciprés, Borges se figura la pesadilla de un mundo sin tiempo, bajo la forma de un falso montaje romano. La fijeza inquietante de las hojas de un ciprés -árbol tan fundamental de la poética virgiliana-, en cuyo marco se prepara el asesinato del narrador, le ofrece un talismán para despertar del sueño y así escapar de su perseguidor. Porque si la maleabilidad y la fluidez de las hojas del ciprés son un signo de lo que Roma es para el que llega de lejos -Quantum lenta solent inter viburna cupressi, así recuerda Borges los versos de Virgilio-, las de su sueño eran "iguales, rígidas y lustrosas y de materia muerta" ${ }^{2}$.

Si de algo estamos seguros al leer el libro de Andrés Rosler, es que su autor nos ha brindado un trazo del republicanismo que intenta tomar distancia de las pesadillas eleáticas de Borges. Se trata siempre de reconstruir un "retrato fiel". No obstante, su fidelidad viene definida por los rasgos ejemplares de la experiencia histórica concreta de la Roma republicana, que el autor denomina "republicanismo clásico".

Tal retrato contiene cinco conceptos-trazos fundamentales: libertad, virtud, debate, ley, patria. Hay un último aspecto de este retrato que le da su pathos polémico, habitando de manera más o menos explícita el interior de las disputas de cada capítulo: el anti-Césarismo. A nuestro entender, esta

1 Borges, J. L., "Las hojas del ciprés", en Borges, J. L., Obras completas. Tomo 3, Buenos Aires, 
polémica es el hilo conductor de la reconstrucción histórico-conceptual: en el análisis de cada uno de los conceptos (por supuesto, esto se explicita al final), Rosler se encarga de mostrarnos su incompatibilidad con el "personalismo" político de César, o su equivalente moderno, el Césarismo. De modo que, en mayor o menor medida, sus disvalores vienen dados por esta polémica. Destaco algunos momentos, de modo esquemático, para hacer visible este modo de leer: la conceptualización de la "libertad para" (eso que Isaiah Berlin llama "libertad positiva") como aquello que puede convertirse en lo opuesto de la libertad republicana: o bien en totalitarismo, o bien en paternalismo (en la idea de "forzar a los hombres a ser libres"), o bien en ambos; la reflexión sobre la virtud moral del desinterés, y sobre el servicio respecto de lo público, como aquello que puede convertir la lucha contra la corrupción en terror; la identificación del involucramiento de los que "toman partido" en el debate como enemigos potenciales del conflicto republicano, que tiene resto, pero que está orientado a la verdad (la diferencia entre conflicto cívico y conflicto faccioso); el señalamiento del personalismo político como aquello que destruye el gobierno de la ley, su autoridad, y más en general la institución republicana de la libertad. Por último: la idea de que la defensa de la soberanía nacional colisiona con el patriotismo republicano, y la postulación de César como el "enemigo natural" de la república.

La otra parte del esfuerzo de Rosler es mostrar, a nuestro entender, que todo esto no lleva a una moralización de la política (al estilo kantiano), sino a un énfasis en (enumero de manera simplificada): la libertad como no dominación, esto es, según la definición ya famosa de Philip Pettit, como "no interferencia arbitraria"; la capacidad de juzgar como capacidad de reflexionar sobre el particular sin que esto sea la simple aplicación de reglas generales; el conflicto siempre con resto (restos disonantes, como dice Rosler, de resentimiento, odio, etc., subproductos de la pérdida política) como dinamizador del debate político; las instituciones como constitutivas de la libertad; la defensa de un particularismo no nacionalista.

En esta breve exposición, que solo querría ser un incentivo para conversar sobre el libro, y sobre los interesantes temas que plantea, proponemos tres cuestiones. En primer lugar, nos detenemos en la idea arendtiana de pensar juntos el concepto republicano clásico de "debate político" y el des- 
empeño de la "facultad de juzgar" -que prosigue Rosler-, así como en la posibilidad de su actualización bajo condiciones de "modernidad" (¿que deja en suspenso Rosler?). En segundo lugar, proponemos otra lectura de la libertad republicana clásica, una que pone en el centro la idea de participación del pueblo (lo cual no supone simplemente una defensa de la "libertad positiva” griega, sino de su lectura romana, que la conserva y amplía). En tercer lugar, sugerimos revisar la ejemplaridad del Bruto republicano.

Adelantamos nuestra posición: a) Respecto de la distinción entre libertad republicana y libertad positiva, es posible que una distinción conceptual a priori, deje de lado experiencias históricas republicanas ejemplares y su relación hermenéutica. Efectivamente, si es verdad que la libertad positiva tiene una fuente griega, no romana, es neCésario pensar su articulación histórica: la complejidad de la democracia clásica, así como la experiencia romana que la hereda y la conserva (tan importante para el republicanismo moderno). b) Respecto del así llamado "Césarismo". Entendemos que lo que Rosler aborda como una enemistad natural de la república, elimina una posibilidad del republicanismo, uno de sus nombres posibles. Más aún: incluso cuando desde una determinada interpretación pueda concederse que es el producto de un republicanismo "perdido en sus extremos" -posición que a veces adopta una línea del republicanismo más aristocrático-, de este solo puede salirse con remedios republicanos. Los cuales no deberían incluir -por razones tanto técnico-prudenciales como valorativas- el asesinato de líderes amados por su pueblo. Por tanto, resulta altamente cuestionable el que la decisión de Bruto de matar a César para salvar la república, y el discurso a posteriori del Bruto de Shakespeare puedan ser vistos bajo el sino de un la virtud republicana. Viendo el desastre posterior: ¿no es Bruto, y no César, quien destruye la república, o la hiere de muerte? Al menos el libro no ofrece ninguna razón de peso para no pensar que la caída de la república en una guerra civil intestina que da origen al Imperio, y a Octaviano, no sea una responsabilidad del mismísimo Bruto y sus impacientes compañeros senadores. 


\section{La discusión republicana y la virtud de la deliberación}

Es una acusación liberal típica respecto del republicanismo que este supone una concepción de la vida buena ya definida, que lo hace incompatible con el pluralismo de los valores moderno. En ese aspecto, entendemos que el libro de Andrés Rosler despliega -incluso si aceptamos que es un libro sobre el "modelo clásico" sin pretensiones de actualización- un modo inteligente de mostrar que, así planteada, esta disputa es estéril. Es neCésario volver a pensar una concepción republicana de la acción política, la que se ubica a igual distancia del terrorismo de una idea sustantiva de bien moral, cuanto de la salida kantiana y su ingenua confianza en la "moralidad interna de la ley".

El núcleo de la argumentación del autor reside en el planteo de cierta epistemología política, que encuentra en el debate juicioso o juzgante el centro de gravedad de la res pública. En este aspecto, como en otros, entendemos que si bien Rosler aclara que se trata de re-construir el republicanismo clásico, esto no se hace con la curiosidad del anticuario sino con el propósito de mostrar una enseñanza o una ejemplaridad para la disputa actual por los "nombres del republicanismo". En el plano de la posible ejemplaridad del debate republicano para el presente, nos gustaría precisar en qué sentido este supone una moral política, o una política moral cuya condición de posibilidad o supuestos deben ser tenidos en cuenta. Como señala el autor en uno de sus mejores capítulos, el republicanismo clásico contiene el elogio de una "virtud deliberativa", o de cierta disposición respecto del habla que tiene en cuenta el punto de vista los demás. Rosler denomina a esta característica como el respeto por una "simetría normativa”, que emparenta el procedimiento republicano al proceder escéptico retratado por el académico Cicerón ${ }^{2}$. No obstante, como parece reconocer en ese mismo capítulo, esta característica supone otras respecto del agente práctico-político, que también es neCésario reseñar para sopesar el alcance -y la posible actualización- de las tesis republicanas, las que dibujan un

2 Para este aspecto específico, destacamos la excelente exposición de Guillermo Lariget, en el primer encuentro para discutir el libro de Rosler, en el Hotel Villa Los Altos, Rio Ceballos, julio de 2019. 
conjunto de sentidos respecto de la acción política en cuanto tal. Dado que ha sido Hannah Arendt una de las figuras filosóficas que de manera más enfática y temprana han acentuado este aspecto, convocamos a la autora de La Condición Humana, para pensar con Rosler.

En primer lugar, se trata de una virtud, lo que indica que el "buen deliberar" no es solo el arte de argumentar bien -y promover el dictum "escuchar la razón de la otra parte" - sino también el de ser capaz de mostrar(se) la propia perspectiva en tanto agente, un "quién se es" que, es cierto, solo aparece cuando aparecemos en público en la discusión con otros. Lo que queremos destacar es que tanto lo que Rosler llama la "simetría normativa" como procedimiento, cuanto la decisión razonable como resultado, son un medio para la formación de una opinión más robusta de un agente práctico, y por ello, para la expresión -y el esclarecimiento- de una identidad práctica como agente político.

En segundo lugar, por eso mismo, la virtud deliberativa supone otra, que Arendt llamaba el "coraje de aparecer" ante otros, esto es, la de la participación misma, que la autora progresivamente comienza a entender como la de asumir la "responsabilidad personal" por el mundo común ${ }^{3}$.

3 Traigo aquí un ejemplo de la propia Arendt: la contraposición entre Sócrates y Platón, que la autora comienza a dibujar desde la escena del inicio de La República. Allí vemos a Sócrates escandalizarse de que dos naturalezas nobles (los hermanos Glaucón y Adimanto) pueden defender la causa de la injusticia, así como la de la justicia, con igual ímpetu. Que no es sólo una cuestión de argumentos, al final, reside para Platón en que, si bien podemos comprender las razones de cada parte, tenemos un ojo interior, que es el que nos permite conocer y actuar en consecuencia en favor de la justicia. Por supuesto, como ha demostrado L. Strauss, se trata de una nobleza del espíritu y no ya del abolengo, y son estos nobles los que han de usar las herramientas mismas de la retórica para que la mayoría, que puede "ver" -que está fascinada con las imágenes de la caverna-, pero no comprender, pueda actuar "como si" viera la verdad misma. De allí la génesis de todos los mitos de las recompensas y los castigos, esos cuentos para viejitas como dice Platón, o cuentos para niños, como dice del mismísimo Homero. De cualquier forma, para Platón, no hay lugar para los maestros de verdad ligados a la tragedia, ni para aquellos que se enfrascan en debates interminables, que lo único que hacen es corromper la verdad. El Sócrates democrático de Arendt, hace algo diferente a la purga platónica. Pues viene a traer un remedio republicano para el dogmatismo de la polis democrática. Se trata de hablar unos con otros, según el modelo no proseguido del "filósofo ciudadano", que ayuda mostrar "quiénes somos" a nosotros mismos, algo que sólo puede ocurrir con otros. Por ello, un aspecto central de ese Sócrates de Arendt, es que no podríamos saberlo sin el intercambio efectivo, y sin los 
Juzgar bien es poder "dar cuenta", a través (entre otras cosas) de la discusión sobre la validez ejemplar de determinados actos de determinados individuos (que dan respuestas buenas o malas en determinadas situaciones), de nuestra propia perspectiva respecto de $-\mathrm{y}$ de nuestra responsabilidad por- el "mundo común". Por eso los "nombres propios" también importan desde una perspectiva pública: por una parte, es cada cual el que juzga, por otra, las acciones de un "alguien" pueden conquistar una validez ejemplar, como el mismo libro muestra ${ }^{4}$. En ese aspecto Arendt indicaba que al juzgar elegimos nuestra "propia compañía": no solo qué aspecto ha de tener el mundo sino "quiénes pertenecen a él conjuntamente" .

En tercer lugar, el propio procedimiento escéptico de "escuchar la razón de la otra parte", no está orientado a la suspensión del juicio, sino a su elaboración. Y, en especial, a una decisión. En ese aspecto, el concepto republicano de debate supone cierta confianza política en que es más probable que se llegue a una decisión razonable de este modo que no haciéndolo. Al juzgar, efectivamente, elegimos "desde una perspectiva pública", "la clase de acciones que se emprenderán [en el mundo común], además de cuál deberá ser su aspecto en adelante, qué cosas deberán aparecer en él"6.

juicios, digamos, que son el producto de esa discusión que nos exige exponer nuestra perspectiva. La importancia de la retórica -Sócrates es un sofista y un maestro de verdad- en ese sentido, es la importancia de hacer visible quien es uno, mostrando cómo "se me aparece" el mundo común. Para este tema cf.: Arendt, H., "Sócrates", en Arendt, H., Promesa de la Política, Barcelona, Paidós, 2008, pp. 43-75.

4 El "personalismo" de los conceptos republicanos no es exclusivamente el producto de una "necesidad psicológica de resguardo, o de una simple sujeción a la autoridad", como señala Rosler respecto de la conceptualización del "Césarismo", sino también el producto de un determinado modo de entender la relación entre los conceptos, y la experiencia histórica que puede volverse ejemplar a través de los juicios políticos. Esto es, por medio del ejercicio de la facultad de juzgar, pueden volverse ejemplares determinadas experiencias políticas y determinados ejemplos de virtud republicana (en muchos casos se trata del modo en que los sujetos reaccionan ante la fortuna, y qué hace de estos comportamientos ejemplares, destacables, para seguirlos, como para no seguirlos). Para la idea de ejemplaridad, cf. Arendt, H., Conferencias sobre la Filosofía Política de Kant, Barcelona, Paidós, 2003, p. 141 y pp. 151-153. Este aspecto del republicanismo ha sido recuperado por Ferrara, A., La fuerza del ejemplo, Barcelona, Gedisa, 2008.

5 Arendt, H., "La crisis en la cultura: su significado político y social", en Arendt, H., Entre el pasado y el futuro, Barcelona, Península, 1996, p. 235.

6 Idem. 
Para resumir, en los debates en clave "republicana" es central la "implicación" del sujeto de conocimiento, que es un agente práctico, por un lado, pero además esta implicación ilumina algún aspecto del propio mundo. Solo conocemos el "mundo práctico" y nuestra posición en él, por medio de esa implicación en los debates que sobre ese mundo se desarrollan en el horizonte de su dimensión "pública". El tono específicamente republicano, al menos del republicanismo clásico, es que esta dimensión pública del mundo no es la del público de críticos (el libro de Rosler a veces parece reservar al demos ese lugar), sino que es la de los actores políticos, en tanto actores. Entendemos que el republicanismo tiene un énfasis en la acción política y en el mundo público concebido de manera republicana. Por eso cuando Andrés Rosler dice que el republicanismo solo nos exige un compromiso con la república ${ }^{7}$, hay que entender que este compromiso es un compromiso bastante fuerte. Arendt llamaba a este compromiso básico como "amor por el mundo", o amor mundi; también "interés en el desinterés”, en una vena más kantiana: todas estas expresiones indican o giran en torno de la virtud republicana del coraje de la aparición pública de un actor político, una condición y un producto del debate republicano.

$\mathrm{Al}$ intentar ampliar el elogio del debate, profundizando en eso que denominamos la virtud deliberativa republicana, no es nuestra intención descartarla por comunitarista, o aristotélica, o inaplicable bajo condiciones de modernidad, sino identificar cuáles son las dificultades para su discusión en el presente. En ese horizonte problemático, destacamos la lectura de Arendt, alguien que sin dudas ha estado preocupada por traer el modo de pensar republicano a nuestros debates. Efectivamente, la autora ha intentado poner en relación la dinámica política republicana con el funcionamiento de la facultad de juzgar en sentido kantiano. Sin entrar en la complejidad de este proyecto, quisiéramos destacar que si bien la pensadora destaca que hay en Cicerón una proto-filosofía del juicio, de raigambre, si se quiere republicana, no obstante, es en Kant en quien se apoya ${ }^{8}$. Esto es

7 Rosler, A., Razones Públicas. Seis conceptos básicos sobre La República, Buenos Aires, Katz, 2016, p. 23.

8 Ha sido esta autora, entre otras, la que ha pensado que su actualización podía ir de la mano con una recuperación de la facultad de juzgar reflexionante kantiana. Esto es, gracias a una facultad que tiene en cuenta lo particular y que a partir de allí busca una validez ejemplar, 
así porque hay algo que ha pasado -obviamente- entre estos autores; eso que vagamente llamamos modernidad, tanto en un sentido positivo como negativo. Diríamos que para Cicerón el valor de la política como espacio privilegiado de la facultad de jugar "en común", es algo que difícilmente entre en el terreno de la deliberación. Todos los juicios políticos, que además tienen una forma hipotética, no imperativa, se hacen en el marco de ese valor indiscutido. El tema con la modernidad es que esto ya no se puede "suponer", sino que debe ser realizado, explicitado: no está dado ese "sentido común republicano". Lo que le interesa a Arendt es que en esa facultad de juzgar tal como Kant la entiende, hay una cosa que se promueve, y que es eso que va llamar amor por el mundo, amor mundi como el centro de las pasiones republicanas. En un marco kantiano: el autor alemán, dice Arendt, descubre una facultad cuya condición es un placer por lo común del mundo, su preservación y su ampliación, central en el horizonte del gran problema que nos lega el totalitarismo. Este problema o conjunto de problemas están vinculados con lo que hace posible el totalitarismo como una "puesta en marcha de desierto". Esto es, como una movilización de procesos de "despolitización" de los agentes y de las instituciones, que se gestan de manera previa: en un extremo, el privatismo civil del "buen padre de familia alemán”, en el otro, el imperialismo que toma a los Estados y su institucionalidad como herramientas de expansión.

En suma, la posibilidad de traer al presente el modelo republicano clásico debe retomar el problema de la virtud de la participación política como tal -en toda su complejidad: como posibilidad de tener en cuenta la perspectiva de los demás, pero también como responsabilidad por lo común, como acción y decisión con otros, como espacio de exploración de

que supone el uso de la imaginación y el sentido común, que entrena la imaginación para ir de visita, que supone un uso representativo del pensamiento, "ponerse en el lugar de todos los otros", que busca el acuerdo pero que no lo tiene asegurado por medio del concepto, que disputa ese acuerdo sin garantías; en fin, todos los tópicos del juicio que recuerda el libro de Rosler, y que sobre todo destaca, con buenas razones, en Cicerón. Hemos desarrollado la lectura arendtiana de Kant en: Hunziker, P., Filosofía, política y platonismo. Una investigación sobre la lectura arendtiana de Kant, Buenos Aires, Prometeo, 2018. 
una identidad política- y su valor ${ }^{9}$. Esto último, el problema del valor de la participación política como tal, ya no puede ser un presupuesto, forma parte de la mínima moralia del republicanismo que debe pensarse bajo condiciones de modernidad.

\section{La libertad republicana como participación cívica}

Eso nos lleva al segundo aspecto que propusimos considerar. Nos referimos a la operación que abre el primer capítulo, "Libertad", separando la "libertad positiva" (tal como ha sido definida en la clásica distinción entre libertad positiva de los antiguos y libertad negativa de los modernos por Isaiah Berlin) de la "libertad republicana".

Recogemos aquí, para comenzar, una perplejidad que tuvo su origen en la lectura del libro de Philip Pettit, Republicanismo. Una teoría sobre la libertad y el gobierno. La perplejidad está ligada a una singular lectura de Hannah Arendt, que no es relevante sino por lo que ilumina respecto al retrato que Pettit lleva adelante del "republicanismo"; tan determinante para su recuperación contemporánea. Así, las primeras páginas de ese libro nos conducen a un análisis que elimina a Hannah Arendt de las filas del republicanismo. La autora judío alemana es borrada del panteón republicano por representar su obra un "populismo" ajeno a esta tradición: una línea populista que identifica libertad y participación democrática en el gobierno de los asuntos comunes. Si bien Pettit reconoce que "los pensadores republicanos consideraron en general que la participación o la representación democráticas eran una salvaguardia de la libertad"10, este no es su núcleo definitorio; por ello, "el creciente énfasis puesto en la democracia llevó a algunos a separarse de la posición tradicional y a acercarse a una posición populista, de acuerdo con la cual la libertad consiste, ni

9 Destacamos, en el marco de nuestro primer encuentro para discutir el libro de Rosler, la excelente intervención de Anna Richter acerca de los problemas modernos ligados a la virtud republicana.

10 Petitt, P., Republicanismo. Una teoría sobre la libertad y el gobierno, Barcelona, Paidós, 1999, p. 10. 
más ni menos, que en el autodominio democrático"11. En ese aspecto los seguidores de la democracia griega dan pie a un giro populista, que cobra forma definitiva cuando
(...) el ideal del autodominio democrático se convirtió en la prin- cipal alternativa $-\mathrm{o}$ al menos, en la principal alternativa entre las distintas nociones de libertad- al ideal negativo de la no-interferen- cia. Pensar que la tradición republicana es populista, como -huelga decirlo- han hechos tantos, monta tanto como afirmar la misma dicotomía que ha tornado invisible al ideal republicano ${ }^{12}$.

Todas estas afirmaciones nos parecen sorprendentes. Por contrapunto, la lectura de Rosler es generosa y amplia, reconociendo en varios pasajes del libro el aporte de Arendt al redescubrimiento contemporáneo del republicanismo. No obstante, acepta el diagnóstico de Pettit en dos sentidos. Por un lado, destacando la lectura arendtiana del mundo romano (sin tener en cuenta la fuente griega). Por otro lado, más allá de Arendt: estableciendo una jerarquía normativa -no solo una diferencia conceptual- de la libertad como participación en los asuntos comunes respecto de la libertad como no-dominación, esto es, como "no interferencia arbitraria" en la vida de cada uno.

Para que se entienda la estrategia que queremos desarrollar en este apartado, en lo que sigue utilizamos la reflexión de Arendt -en especial la que encontramos en La Condición Humana- para mostrar la posibilidad de entender la libertad republicana de manera diferente. Esta diferencia no es solo una diferencia conceptual, sino una que aborda la centralidad de la recuperación romana del mundo clásico griego como un acontecimiento central que debe ser tenido en cuenta para analizar la propia experiencia romana y su "filosofía política", su elenco de conceptos.

En primer lugar, proponemos dejar en suspenso la etiqueta de "neoaristotelismo" para todos los autores que vuelven al mundo griego en clave republicana. Nos inclinamos, en este caso, por pensar el "neoaristotelismo" de la autora de La Condición Humana, como una defensa republicana de la libertad de participación como centro de la dinámica política. Es intere-

\footnotetext{
${ }^{11}$ Idem.

${ }^{12} \mathrm{Idem}$.
} 
sante que la autora vea en esa libertad de participación una fenomenología de la praxis política como espacio de revelación del mundo político y de los actores en tanto agentes. Esto es, que haga depender el concepto de libertad de una teoría de la acción política y de la agencia. En la base de la dinámica de la polis griega, Arendt cree descubrir la "experiencia pre-polis" del mundo público como espacio de aparición y revelación de los hombres en tanto hombres -hay que retener el plural-cuya existencia y permanencia se obtiene por la articulación entre praxis y discurso, y por el carácter plural del logos que esta última supone.

Lejos de idealizar el mundo clásico, por otra parte, la autora manifiesta en La Condición Humana los límites de este modelo, con ojos casi romanos. Lo interesante para nuestra discusión es que ninguno de esos límites tiene que ver los "desmadres" de la participación del demos, sino con la posibilidad de conservarla, y ampliarla. Ello exige, según la autora, por una parte pensar en una mayor complejidad institucional - una institucionalidad de la praxis política republicanamente comprendida-, por otra parte, pensar en una mayor complejidad de la subjetivación política, de la agencia-que incluye la libertad respecto de la política, con el socrático descubrimiento de que no estoy con otros, sino también conmigo mismo.

Este conjunto de problemas serán retomados por el mundo romano, para la autora, pero sin abandonar esa idea de libertad como participación, sin cuyo sentido no se entendería el descubrimiento romano de la importancia de un gobierno de las leyes y no de los hombres. Arendt valorará este descubrimiento, pues supone una salida política a las tensiones de la polis de Pericles, que ella misma señala en su libro más "griego". Efectivamente, La Condición Humana establece una serie de juicios severos, en los que la ciudad es cuestionada en la medida en que no logra conservar, redefiniéndola, aquella experiencia pre-polis de la acción política como experiencia de libertad de los hombres, que tiene su expresión primera en el espacio de la prosa homérica. A riesgo de ser esquemática, señalo tres aspectos de esta crítica.

En primer lugar, la autora indica que la estrecha vinculación entre acción y discurso no se conserva en el "más hablador" de los cuerpos políticos, el que progresivamente convierte al discurso político en un medio de "persuasión" - un instrumento neutro-, y no de explicitación de una 
relación personal, prácticamente mediada, con el mundo común -dice Arendt-, el lenguaje como un medio de responder a "lo que nos pasa", y de asumir una "responsabilidad" por lo que "nos pasa".

En segundo lugar, insiste en las dificultades de la agonalidad griega, cuyo énfasis en la "distinción" hace palpable el "ser distinto", pero corre el riesgo de socavar la visibilidad del principio de igualdad. Efectivamente, la autora señala que, dado el "carácter individualista" del concepto griego de acción se acentuó en exceso

(...) la urgencia de la propia revelación a expensas de otros factores (...) Como tal, pasó a ser el prototipo de la acción para la antigüedad griega e influyó, bajo la forma del llamado espíritu agonal, en el apasionado impulso de mostrar el propio yo midiéndolo en pugna con otro ${ }^{13}$.

Este aspecto se conecta con otro, central para la consagrada interpretación de M. Canovan. La experiencia de la prosa homérica es la de uno que se aventura en una empresa, y que es seguido por otros como un primus inter pares: uno que se destaca entre iguales, y en la medida en que son iguales. La acción colectiva no supone la igualdad de la homogeneidad, sino una igualdad de singulares que son diferentes.

Por último, encontramos los problemas de una excesiva confianza en la realidad de la praxis y el discurso (que para la interpretación de la autora debe pensarse en su esencial articulación con el poder como dynamis ${ }^{14}$ ) para preservar su memoria póstuma: la "gloria" de los actores y el "sentido" de sus actos. Es interesante que este señalamiento sea dirigido a la Oración Fúnebre, y a la creencia allí orgullosamente defendida de que "el íntimo significado del acto actuado y la palabra pronunciada es independiente de la victoria y la derrota y debe permanecer intocado por cualquier resultado

13 Arendt, H., La Condición Humana, Barcelona, Paidós, 1993, p. 217.

${ }^{14}$ Aquí aparece el concepto de "poder" como "posibilidad" de los hombres que actúan y hablan, y no como una propiedad del individuo, o sea, "una intercambiable, mensurable y confiable entidad como la fuerza”, Arendt, H., op. cit., p. 223. Además, surge el problema de su "perduración", que no es solo institucional, sino también de "sentido", y de "herencia". 
final"15. A los ojos de la autora, si bien este aspecto supone una valorable y antigua fe en la política como tal, deja de lado, al menos como problema político, aspectos centrales ligados a la "finitud" de la propia praxis. Y, en especial, no resuelve una inquietud que ya está presente en el texto sobre Sócrates de 1954: la pregunta por una dimensión pública no estrictamente política, ligada al "testigo" y habilitada por el "pensamiento", por una parte, y la pregunta por la ley, y la estabilidad brindada por la ley, por otra.

En el horizonte constituido por el conjunto de problemas de una polis que no asume sus limitaciones, Arendt destaca el modelo romano como un conjunto de invenciones fundamentales, en especial vinculadas con la institucionalidad republicana que llega hasta nuestros días. Como bien señala Rosler y toma correctamente como fuente, Hannah Arendt es una de las primeras en mostrar la importancia de la experiencia romana para pensar en algunos conceptos centrales de un redescubrimiento (gracias a ella) del republicanismo moderno: en Maquiavelo, Montesquieu, Tocqueville. Respecto de esa experiencia romana, Arendt destaca, sucesivamente: una interpretación política de la ley como constitutiva de la libertad de todos, como relación y no como límite; entre acción política, ley e institución republicana de la libertad, la positividad de la división para la conservación del poder, la centralidad de la promesa y del juramento como centro de la legitimidad de las instituciones republicanas de la libertad, la necesidad de la "autoridad de la ley", no de los hombres.

No obstante, en esta operación de institucionalización, de domesticación de la salvaje Atenas, valga la ironía, Arendt señala dos cosas. De un lado, que para el mundo romano la libertad está ligada a la participación de la plebe en los asuntos públicos y a la capacidad de Roma de generar alianzas. Ambas nociones articulan esa libertad "positiva” griega. Así, contra la tesis de Pettit la institucionalidad republicana es un medio para la libertad como participación, y no a la inversa. Los hombres participan en la res pública no porque no quieran ser dominados, sino porque son libres cuando actúan con otros, y en tanto actúan. El problema político no es el

15 Ibid., p. 220. Cf.: Tucídides, II, 41. En este caso, La Condición Humana abre la pregunta por la centralidad de la narración histórica como "artefacto" para la constitución misma del espacio político, algo que la autora se encargará de explicitar en otros textos. 
de "racionalizar" la participación, sino el de institucionalizarla: cómo conservarla y ampliarla. Del otro lado, Arendt entiende que sea posible mirar el problema político republicano como el de una "racionalización"-esto es, como una teoría que busca "civilizar" sus componentes democráticos más salvajes- dado que son los propios espectadores filósofos romanos, los que se ubican por detrás -dan un paso atrás- de sus invenciones como actores de la república romana. Sabida es, en este sentido, la interpretación arendtiana del final de La República ciceroniana como escrito crepuscular, que apuntala un lugar en la eternidad para soportar el neCésario fracaso de las causas más nobles. Un placer retrospectivo y melancólico del fracaso -de Cicerón el filósofo-, es lo que queda del amor por la patria del senador romano.

Ahora bien, y en este marco modificado, uno podría pensar que tenemos en Bruto - un actor fundamental para la herencia republicana- la filosofía política romana que Arendt señaló que nunca existió, al haber tomado Cicerón el mandato de respetar la autoridad filosófica griega. ¿Podría ser así? En el próximo apartado sugerimos que esto es, al menos, dudoso.

\section{El Bruto republicano de Rosler}

¿Había que matar a César? Rosler nos dice que hay una respuesta veraz en la acción del propio Bruto, héroe republicano que consuma el asesinato junto con sus compañeros senadores, puñal tras puñal inmortalizado en imágenes diversas de nuestra cultura. Como ha defendido con buen tino liberal Andrés, en su libro no se defiende el asesinato (sic), sino que este aspecto de su argumentación forma parte de su intento de hacer un retrato de los principios básicos del republicanismo clásico. La fuerza del anti-Césarismo republicano se mide por la asunción del costo que implica ese asesinato, precisamente.

Nos interesa destacar aquí dos cuestiones: una vinculada con las fuentes de Rosler, y por tanto con la "fidelidad" del retrato; otra con el ejercicio de cierto anacronismo, si se nos permite, respecto del fracaso de este acto político y su enseñanza para la compleja tradición republicana. 
Respecto de las fuentes, como sabemos, no encontramos en ninguna fuente clásica el discurso "republicano" de Bruto. Solo sabemos por Plutarco que Bruto dio un discurso ante la multitud, luego de la muerte de César, en defensa de sus acciones, como señala Rosler en la nota 70 de su libro; pero "no dice nada sobre contenido, solamente hace referencia al estilo espartano de la correspondencia de Bruto" 16 . Tampoco encontramos una defensa sin más de este crimen entre los historiadores de Roma ${ }^{17}$. Por último, sabemos que Cicerón no es convocado en la revuelta que lleva al asesinato de Julio César, y tampoco encontramos en su obra ninguna justificación respecto de este hecho ${ }^{18}$. Nos preguntamos, ¿ este silencio no nos permite inferir ninguna conclusión histórica sobre la pertinencia de incorporar la condenación de César como una marca natural del republicanismo?

Rosler elije otro camino, uno a nuestro entender interesante: buscar en el Julio César de Shakespeare, el discurso perdido de Bruto, suponiendo que sea posible esta transposición. No obstante, aquí también nos fallan las expectativas. Rosler nos indica que la enunciación del Bruto de Shakespeare, es

${ }^{16}$ Rosler, op. cit., p 139.

17 Tal como el propio Rosler señala, si encontramos en Suetonio la idea de que existen razones públicas para esa muerte. No obstante, esa afirmación se sigue luego de que el mismo autor haya hecho un encomio de las grandes virtudes políticas de César. Luego de ese encomio Suetonio señala "Sin embargo, predominan sobre estos otros actos y dicho suyos, que hacen pensar que abusó del poder y que fue asesinado con razón”, Cf. Suetonio, Vidas de los doce Césares (César-Augusto), Madrid, Gredos, 1992, Libro I, 76. También encontramos en Tácito la idea de que "el homicidio cometido en la persona de César dictador parecía a unos acto generosísimo y a otros maldad execrable", Tácito, Anales, Barcelona, Planeta, 1990, libro I, 8.

${ }^{18}$ Está documentado que Cicerón no participa de este asesinato. Plutarco señala: "En cuanto a las conspiración que se estaba concertando contra César, no tomó parte en ella, a pesar de que era de los mejores amigos de Bruto y daba la impresión de que a él más que nadie le disgustaba el estado en que se encontraban los asuntos públicos (...) Pero los conspiradores recelaban de su naturaleza, que consideraban carente de audacia, y de su edad", Plutarco, “Cicerón”, en Vidas Paralelas, Madrid, Gredos, 2011, 42.1-2. Incluso el propio Julio César de Shakespeare, que Rosler toma como fuente, y que sin dudas ha leído a Plutarco, incluye en su obra un coloquio entre Bruto y Casio, en que el primero excluye a Cicerón de la conspiración. Efectivamente, Casio propone sumar al prócer republicano, incluso Metelo agrega el "prestigio de sus canas", pero Bruto responde "no extrememos la franqueza/pues él jamás seguirá/los planes de otro hombre”, en Shakespeare, W., Julio César, Trad. De Alejandra Rojas, Norma, Bogotá, 1999, 2.1.141-52. 
malograda y "personalista", dado que no hace honor al concepto republicano de "escuchar y exponer la razón de la otra parte". Efectivamente, la mayoría de las preguntas retóricas que formula Bruto al pueblo, "intimidan o acosan al público en lugar de proponer un debate, e incluso la pausa hecha 'para una réplica’ no permiten en realidad respuesta alguna ni por lo tanto, debate genuino alguno; Bruto sostiene que para oponérsele hay que ser abyecto, bárbaro, vil, en una palabra, estar en contra de la república"19.

Si bien Rosler acepta mucho antes de su capítulo final los problemas que este discurso trae al concepto de debate republicano que ha propuesto, no obstante: a) Deja de lado la complejidad del discurso que sigue al de Bruto y su aparente éxito (que en la pieza del propio dramaturgo inglés

${ }^{19}$ Rosler, A., op. cit., p. 148. Respecto del análisis de Rosler, nos gustaría enfatizar que el problema no es estrictamente la "personalización" de los argumentos, sino que esta personalización se lleve adelante cuando ya han ocurrido los hechos, esto es, el asesinato de César, reforzándose así la no discusión pública sobre "qué es lo que hay que hacer" para salvar a la república. Como señala el mismo Rosler, "la decisión de Bruto está tomada y en todo caso la discusión es cómo presentar la acción ante los demás", Ibíd., p. 150. Por otra parte, en cuanto a la presentación de la acción misma, no encuentro objetable el inicio del discurso de Bruto: "Romanos, compatriotas y amigos queridos, permítanme defender mi causa y guarden silencio para oírme bien. Y para creerme, crean en mi honor y respétenlo. Censúrenme con su sabiduría pues así serán los mejores jueces. Si en esta asamblea está presente algún amigo querido de César, a él le digo: que el amor de Bruto por César no fue menor que el suyo. Si este amigo, entonces, preguntara porqué Bruto se levantó contra César. Mi respuesta sería: no porque amara menos a César sino porque más ama a Roma", Shakespeare, W., op. cit., 3.2. 13-20. El problema es que inmediatamente Bruto excluye del "amor a Roma" a todos los que aman a César. Con ello no tiene en cuenta -incluso para criticarlo- el amor popular a César como un amor a aquel que defiende la república. $\mathrm{Si}$ tomamos las preguntas que siguen, efectivamente, ya no se trata de una discusión acerca de la república que apoyamos de manera razonable aunque contrapuesta, sino acerca de una posición racional y una irracional, absolutamente moralizada: “Preferirían que César viviera, y morir todos como esclavos a que César haya muerto y vivir en libertad? Puesto que César me quiso, lloro por él; porque tuvo fortuna, celebro su buena suerte, porque fue valiente, lo honro. Más como era ambicioso, lo maté. Hay lágrimas para su amor. Alegría para su fortuna, honra para su valor, y muerte para su ambición. ¿Quién, entre ustedes, es tan abyecto que querría ser esclavo? Si hay alguno, que hable, pues lo he ofendido. ¿Quién, tan bárbaro que no quisiera ser romano? Si hay alguno, que hable, pues lo he ofendido. ¿Quién, tal vil que no ama a su patria? Si hay alguno, que hable, pues lo he ofendido". Es ante estas preguntas retóricas que Bruto "espera en silencio una respuesta", la cual dado obviamente el tenor de las oposiciones, no llega, concluyendo así "entonces no he ofendido a nadie", Ibid., 3.2. 20-29. 
que toma como fuente no es tal). Es el discurso que sigue, el de Antonio, el que conquista al público y lo hace dada su mayor complejidad y su invitación a hacer lugar a "la razón de la otra parte", un auténtico ejercicio de debate republicano. $b$ ) Nos ofrece en su capítulo final el elenco de razones objetivas para hacerlo (esto es, la teoría política que el Bruto republicano debería haber articulado): "Para ser totalmente justos con Bruto (...) lo que parece ser una racionalización retórica podría ser en realidad la conclusión neCésaria de un razonamiento que partiera de premisas republicanas bastante estrictas" 20 .

Quisiéramos al menos sugerir la hipótesis de que, incluso si nos movemos en el plano del texto shakesperiano, podemos encontrar allí razones republicanas -en su contenido y en su forma- para poner en duda la legitimidad del asesinato de César. Es Antonio, no Bruto, el que señala los dos lados del asunto y su complejidad, incluso cuando está claro que está en contra del asesinato de César: por lado insiste en que Bruto y Casio son hombres honorables, y que no duda de ello; por otro lado, no obstante, indica que eso que entienden por "ambición", puede ser descripto de otra manera por el pueblo:

Era mi amigo, justo y leal hacia mí/Pero Bruto dice que era ambicioso/ y Bruto es un hombre honorable/Trajo muchos rehenes a Roma. Cuyos rescates llenaron de oro nuestras arcas/ ¿Por eso se pensó que César era ambicioso?/ Cuando los pobres lloraban, César lloraba con ellos/¿no está forjada la ambición en materia más dura?/ Pero Bruto dice que era ambicioso, y Bruto es un hombre honorable/ Todos vieron en las Lupercales/que tres veces le ofrecí la corona real/y tres veces la rechazó. ¿Era eso ambición?/Pero Bruto dice que era ambicioso/y, sin duda, él es un hombre honorable. No hablo para refutar las palabras de Bruto/ sino para declarar lo que yo sé/ En vida todos le amaron, y no sin causa/ ¿Qué causa les impide honrarlo en la muerte?/¡Ah, sensatez! Te has alojado en bestias sin alma y dejado a los hombres sin razón ${ }^{21}$. 
¿A qué "razón" apela Antonio? Se trata de tener en cuenta la razón política -el juicio- implicado en el amor a César. ¿Por qué Rosler ubica del lado de la "mala retórica" al discurso de Antonio? En este punto, me sumo a la inquietud que nos deja Eduardo Rinesi, en el último capítulo de Actores y Soldados. Sería interesante, señala el autor, preguntarnos si:

¿Acaso el entusiasmo tiranicida que justifica el asesinato de los líderes populares como Julio César es un entusiasmo propio del ideario republicano en general o si corresponde a una adhesión a un tipo o modelo de república en particular: la que la historia de las ideas políticas califica como "aristocrática", minoritarista y siempre recelosa frente a los caudillos, por oposición a otro tipo de república, también posible y llena de prestigio teórico, importancia histórica e interés político que es la república que podemos llamar, y que se ha llamado "democrática" o "popular"?22.

Teniendo en mente esta pregunta -que abre la posibilidad de pensar una diferencia al interior del republicanismo-, se podría afirmar que Rosler ha tomado partido por una definición bien delimitada, cuyo fin es definir lo que este no es, y así disputar un nombre para el presente.

Respecto de este intento, sugiero, para concluir, una preceptiva conjetural de la epistemología republicana romana, de sus "razones públicas".

En primer lugar, existe un argumento que cabe aplicar a todo el espectro del republicanismo, en todas sus variantes, más o menos populares, más o menos aristocráticas. Como bien señala Rosler, un aspecto fundamental es entender el "realismo republicano". Este indica que no se puede hacer cualquier cosa con las palabras, al menos si uno quiere ser eficaz con ello. Roma enseña a Grecia no solo un conjunto de invenciones políticas e institucionales, sino también, como el mismo Rosler se encarga de mostrar en numerosos pasajes muy virtuosos de la argumentación, que el "realismo", no el "conservadurismo", es un aspecto central del tipo de razonamiento republicano. Esta dimensión no lo hace inmoral, sino el representante de una moral política que puede hacer lugar, en términos

22 Rinesi, E., Actores y Soldados. Cinco Ensayos hamletianos, Buenos Aires, Editorial de la UNGS, 2018, p. 119. 
aun republicanos, a los liderazgos fuertes. Esto es, que se trata de una "posibilidad" de la república, y no de su enemigo natural. El resultado efectivo del asesinato del César debe decirnos algo sobre la falla epistémica de Bruto y sus amigos senadores.

En segundo lugar, señalamos algo que ya adelantamos al hablar del juicio político republicano. Creemos que esto también se aplica a todas sus variantes: el test seguro de su veracidad es, como señala Rosler, el "escuchar la razón de la otra parte", porque solo ese modo de ser público habilita una decisión razonable, y, en general, un espacio público republicano fundado en "el compartir las palabras y los actos con otros que son sus iguales". Bruto no discute su temeraria acción con el pueblo, y en este aspecto no es ni demagogo ni doctrinario, sino sencillamente un conspirador. Que exponga sus razones ex post facto no es un argumento a su favor, sino al contrario. Insisto: podemos entender este "escuchar las razones" de manera más aristocrática, como un "dar razones" ante al pueblo, como control público (así lo entiende Pettit), o como un buscar las razones del pueblo, o "hacer lugar" público para su reconocimiento, formación y expresión (en el sentido en que entiendo lo entiende Arendt). Pero incluso en su vertiente aristocrática, el republicanismo no puede incluir un desprecio por el juicio del pueblo, como uno que es oscurecido por el amor irracional, esto es, como un no-juicio.

Dicho todo esto, tal vez sea bueno empezar a discutir este episodio sangriento de la historia republicana, y su ejemplaridad. Entendemos que Rosler nos brinda una clave fundamental, al señalar la vinculación entre razón pública, debate y republicanismo. Tal vez este sea el camino -junto al intento de pensar la multiplicidad interna del propio republicanismopara despertar de su sueño de hojas lustrosas y sin vida al propio nombre de "la república". 


\section{Bibliografía}

Arendt, H., "Sócrates", en Arendt, H., Promesa de la Política, Barcelona, Paidós, 2008, pp. 43-75.

Arendt, H., Conferencias sobre la Filosofía Política de Kant, Barcelona, Paidós, 2003.

Arendt, H., "La crisis en la cultura: su significado político y social", en Arendt, H., Entre el pasado y el futuro, Barcelona, Península, 1996, pp. 209-238.

Arendt, H., La Condición Humana, Barcelona, Paidós, 1993.

Borges, J. L., "Las hojas del ciprés", en Borges, J. L., Obras completas. Tomo

3, Buenos Aires, Emecé editores, 1989, pp. 485-486.

Ferrara, A., La fuerza del ejemplo, Barcelona, Gedisa, 2008.

Hunziker, P., Filosofía, política y platonismo. Una investigación sobre la lectura arendtiana de Kant, Buenos Aires, Prometeo, 2018.

Petitt, P., Republicanismo. Una teoría sobre la libertad y el gobierno, Barcelona, Paidós, 1999.

Plutarco, Vidas Paralelas, Trad. Carlos Alcalde Martín, Madrid, Gredos, 2011.

Rinesi, E., Actores y Soldados. Cinco Ensayos hamletianos, Buenos Aires, Editorial de la UNGS, 2018.

Rosler, A., Razones Públicas. Seis conceptos básicos sobre La República, Buenos Aires, Katz, 2016.

Shakespeare, W., Julio César, Trad. De Alejandra Rojas, Norma, Bogotá, 1999.

Suetonio, Vidas de los doce Césares (César-Augusto), Trad. De Rosa Agudo Cubas, Madrid, Gredos, 1992.

Tácito, Anales, Barcelona, Trad. De Carlos Coloma, Barcelona, Planeta, 1990.

Tucídides, Historia de la Guerra del Peloponeso, Trad. De Juan José Torres Esbarranch, Madrid, Gredos, 2000. 